ISSN: 2576-8875

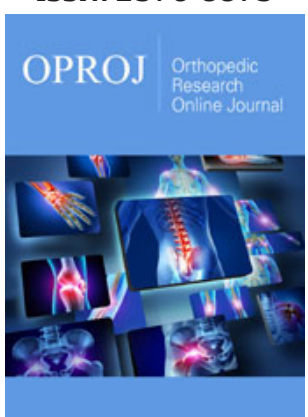

*Corresponding author: Hayrettin Gümüșdag, Bozok University, Faculty of Sport Sciences, Yozgat, Turkey

Submission: 趼 May 28, 2021

Published: 俔June 04, 2021

Volume 8 - Issue 2

How to cite this article: Hayrettin Gümüşdag*. Aggression in Football: A Field Study. Ortho Res Online J. 8(2). OPROJ. 000685.2021. DOI: 10.31031/OPROJ.2021.08.000685

Copyright@: Hayrettin Gümüșdag, This article is distributed under the terms of the Creative Commons Attribution 4.0 International License, which permits unrestricted use and redistribution provided that the original author and source are credited.

\section{Aggression in Football: A Field Study}

\author{
Hayrettin Gümüşdag* \\ Bozok University, Faculty of Sport Sciences, Turkey
}

\begin{abstract}
Football, peace, brotherhood and love and a social network that brings together all segments of society. It can be expressed as a branch. However, the embodiment of the perception of winning and losing and the economic The structure of football with its evaluation with measurements and the way it is perceived has changed. Field in football violence, aggression occurring in or in their area and this is the main reason for their deviant behavior. We can show the change not spontaneous. The reasons for this process include mass media, club managers, athletes, referees, coaches, spectators, etc. other elements involved in sports we can say. In this context, a review of my current studies and literature. The aim of this study carried out with and to explain the reasons for the behavior by explaining the aggression.
\end{abstract}

Keywords: Aggression; Aggressive behaviors; Athlete; Football; Sport

\section{Introduction}

Today, football is a sport branch that drags people in many countries of the world. The intense interest in football, which has entered the history of world sports since the 1800s, is due to the fact that football is easy to understand and playable as a game. Regardless of its spread and speed, football is now the most widespread and most invested sports branch in the world. Such intense attention inevitably has made this sport branch a potential market, even an industry with huge boutiques. This feature of football has caused a continuous development and change within itself. The rules of the game and training techniques are constantly being renewed in a way to increase and protect this interest. Now many branches of science have begun to enter football, and they are trying to contribute to this sport branch in a way that will increase the performance of the football player. Thanks to these studies, football has become a branch that requires more intense physical strength and tactical knowledge and skills. Winning, being a champion, scoring goals, attracting people's attention has gained much more importance now. As a result, the level of struggle to achieve the goal has also increased [1].

The development of the rules of the game to increase the pleasure of the game and to protect the star players has pushed the relevant units to work towards taking more effective precautions day by day in this intense struggle. The rules regarding fouls are constantly changed or renewed. In the last 20 years, there has been a large increase in the number of physical contacts in play compared to the past. In line with the advances in human physiognomy in terms of using the physical power of our players, FIFA (Federation Internationale de Football Assocation) has taken a series of precautions to protect the players in duo struggles. FIFA explains its view on fouls as follows:

"The game of football is a hard game. The referee must give permission, even if the manners and ball-related interventions to be made during the game are harsh. "So the referee will pay attention to two things while playing the game.

1. The action definitely does not target the opponent,

2. The move is aimed at winning the ball. 
The removal of the intent element from the $12^{\text {th }}$ rule and the replacement of the concepts of careless, uncontrolled and disproportionate use of force while making it easier, responsibility is attributed to the players. The player must be careful not to hurt the opponent while making his intervention. Otherwise, he must bear the penalties (direct free kick, caution or sending-off) that will be brought about by his misconduct. In sliding from behind and from the side, if the opponent's feet are interfered with before the ball, the player will be cautioned in addition to the direct kick. However, the player in control of the ball does not have a chance to take precautions against interference from behind or from the side or to be protected from injury. In sliding operations, the feet should not be off the ground. If a player who wants to interfere with the ball by sliding between the opponent's feet has raised one or both feet and his action is dangerous to his opponent, the referee must stop the game without waiting for the result of the action and show the player a yellow card. Because the referee should be energetic to anticipate and avoid any injuries that may arise [1].

It should not be forgotten that attempts to disrupt the opponent's game without the intention of playing the ball, to prevent his atag, should be considered as unsportsmanlike behavior and players who attempt to do so should be punished with a yellow card. Acting or attempting to harm the opponent is considered and applied as punitive actions. Especially, it is among the practices of Football Federations to detect deliberate movements that will harm the opponent, even if the referee does not see it, and punish the person who does the action from the video [2].

In a sports branch that affects people so much socially, it is obvious how the sportsmen, on which the attention is focused, acting deliberate and injurious to each other will affect the crowd watching the matches. Therefore, the effect of fouls committed by players against each other is not limited to the player who was fouled. Fouls in football, which is a social activity, watched by thousands of people, also affect the audience. Especially deliberate fouls have been found to have a greater effect on the audience [3].

The importance given to winning leads to the acceptance of many illegal tactics. In this way, fouls committed professionally during the match are also on the agenda. In football, for example, a defender prefers to drop the opponent outside the penalty area rather than pursue the opponent or put his side at risk of goal. Such behaviors are generally regarded as "good punishments" in sports branches with high competition. In terms of aggressive behavior, such fouls fall into instrumental behaviors. It is used as a foul tool [4].

A 50k player who is internationally renowned and known for his tough playing style, explains that playing hard is a natural thing. For example, Jupp Kapellmann, one of the former East German National team and Bayern Munich team players, says the following: "I am not much different from an animal, we are fighting a struggle for existence with all possibilities. Anyone can try to destroy the other. "He has not been able to train the innate tendencies of emotional aggression in players of this type and exist in every human being. These kinds of emotions are present in every human being, but they can be trained and controlled over time. This tour connects the viewer and reflects the most important philosophy of high-level games. The aggressive attitude is not only frustrated with professional sports. Such events have recently started to occur in many friendly matches and school tournaments. Therefore, school administrators, trainers and administrators have begun to look for the most effective ways to solve this problem. The act of the athletes with the stops of aggression and their approach to the opponent in this way is not necessarily considered as an acceptable behavior in sports [4].

It is known that the history of the tendencies of violence and aggression is as old as the history of the human being all over the world, and that they continue to exist, albeit in different forms, by evolving and evolving with human beings. In sports; It is observed that in more specific forms, maturing in line with the flow of time, it has been kept alive with its anthropological and folkloric dimensions, with the acceptance or personal participation of the people. A person's conscious and deliberate behavior towards psychologically or physically damaging his social stage is called "aggression", and the relatively persistent tendency to show aggressive behavior in the person is called "aggression " [4].

Aggression is always considered in relation to the relevant situation that led to the action. Increased aggression feature may increase the possibility of engaging in aggressive behavior. Symbolic and symbolic movements or phenomena that discharge aggressive behaviors in humans by satisfying them, become apparent only as an element of violence with acts and images, are called "element of violence". It is possible to evaluate the elements of violence in two different categories, material and spiritual. Material violence elements against a person or group by using force or by using physical force, hitting (assaulting) with hand, foot or any means, breaking any part of the body, falling by throwing, destroying, fainting, etc. It consists of actions aimed at mutilation, such as. It is possible to see these actions most uniquely on sports grounds. Sports competitions and conditions of competition provide a suitable ground for demonstrations of aggression [3].

As the frequency of body contact increases, the likelihood of aggression increases. In this regard, sports activities are divided into three groups according to which case they allow body contact: In the first group, there is "individual combat sports" (combat sports) that give the most opportunity to exhibit aggression. 38 Bodily aggression applies only to sports that allow close contact and individual combat. such as putting on hands, kicking or punching, hitting an opponent with sports equipment. From the point where the rules are violated, the transition to true aggressive behavior occurs. Offensive behavior may be mentioned when acting with the intention of harming an opponent by violating the generally accepted rules. 9 Team sports that allow body contact in certain cases and play with the ball (such as football, handball, basketball, etc.) are in the second group. There is no such contact in sports such as volleyball, athletics, tennis, cycling and golf that make up 
the third group. However, this does not mean that aggression is not seen in these sports. Pulling off an opponent's shirt while running, dropping your opponent off the bike while racing are situations that can be encountered in sports. Also, it is important not to classify aggression with just competition. Aggressive behavior may be exhibited during training or after the end of the challenge [3].

The elements of spiritual violence, on the other hand, consist of acts and actions that have the power of humiliation against a person or group, by insulting or mocking, based on psychological attrition, verbal, symbolic behaviors or gestures and gestures. The use of small degrading, hurtful, mocking words, directly or indirectly humiliating, defeating, attacking one's personality, making constant obstacles with harsh and rude speech shows that anger has a wide range of expression possibilities along with verbal aggression. Kufur is a verbal expression of the element of violence. Denial, which reaches the most sacred values for a person, starting with the words that others value, love, respect, degrade objects or personalities, is the worst and most violent form of verbal aggression [5]. Insulting or ridiculing an opponent or referee in order to cause pain and anger, while entering into verbal aggression; signs of aggression, punch, tennis racket, etc. It includes threatening the opponent with such tools. Likewise, this kind of aggression can be displayed with some hand, arm movements or glances [3].

According to Kiper (1984), while aggressive behaviors are carried out in an experimental environment in many studies in the field of social psychology; The sportive environment has the feature of being a natural environment in the emergence of this behavior. Because inhibition, which is thought to cause aggression, is always present in sport. It is the case that the opponent constantly tries to prevent a purposeful move. The sportive environment is also a suitable environment for taking and imitating aggressive behavior as a model, and to learn more accurately. For all these reasons, the results of our work can be beneficial in controlling the aggressive behavior of football players, preventing or minimizing violence in football, which has millions of viewers. Again, with the revealing of the reasons for the aggressive behavior of the football player as a result of this research; It can be ensured that spectators, trainers, managers and athletes are informed and trained in this direction. In addition, as a result of our work on this subject, it can be determined how the athletic performance is affected by the aggressive behaviors of the football players, and if the aggressive tendencies of professional athletes differ greatly in terms of sports performance, this aspect of feat can be used in the direction and selection of the athlete. In this study, it is important to examine the sociological and psychological structure of football players and their on-field aggression situation, to determine the reasons for the aggressive behaviors they exhibit in the football altars, and the suggestions they will put forward for minimizing the aggressive behaviors.

Professionalization in an individual's behavior gives the question whether it is more important to win in the game, to play well, or to play fairly and in accordance with the rules. As behavior becomes more professional, the emphasis is shifting towards winning. On the other hand, the understanding of the trainer is also important to the seal. The instructions given as "to win at any cost" cause great stress and reactive aggression. Therefore, how the athletes are motivated about their rivals is of great importance [1].

The aggression that exists in human psychology. It appears to be reflected in fouls in professional football competitions. As a result of many analyzes and classifications of aggression, it has found a place in these classifications that occur in fouls. If we consider these results in terms of ordinary people and also from their perspective, who, like football, are no longer a series of sports encounters and gentlemanly competition, constitute a sector of social phenomena that play a role in very high material and psychological parameters and lead to results that deeply affect the masses. We need to examine it in a few different ways. In the past, aggressive behavior was generally defined as deliberately harming another person. However, these definitions do not apply to sporting events, as behavior that may harm the opponent during the competition is within the rules. Therefore, an extra criterion should be determined for the sports competition rule breaking. Then, aggressive behaviors should not only be defined as the action applied to a person, but also as breaking the rules (Silva, 1979). Rule breaking behavior should of course be punished by the referees. With the help of penalties and sanctions, aggressive behavior can be controlled even more. In particular, the basic principle of Fair Play, the opposite hostile aggressive behavior is also prevented [5]. As a result, we can associate fouls committed in professional football with aggression. We arrive at this conclusion by dividing fouls into categories. Because in sports psychology, the aggressive behavior of the players is under two headings are classified, these are; instrumental (tactical) aggressive behavior and hostile (hostile) aggressive behavior. In both types of behavior, the aim is to physically or psychologically harm a targeted person. Instrumental aggressive behavior is used strategically to undermine advantage if it serves a specific purpose. In this case, the cognitive and learned process (social learning theory) is complex, and the player must be instrumental in improving the ratio between cost / value (eg punishment by the referee) and profit (eg easily winning the ball or making the other team losing the ball grossly) at the right time and place. Learn to use (tactical) aggressive behavior. Accordingly, a learned behavior overlaps with the social learning-aggression theory of aggression [6,7].

\section{Conclusion}

Fouls are one of the trespassers of football. There is no foulfree football magi, because football is both a team game and allows physical combat and contact with the opponent player. It is difficult to talk about this in volleyball and tennis. Especially in professional competitions, the material and moral wins obtained as a result of winning the match prevent the players from controlling their behavior from time to time and exhibit aggressive behaviors when they fail to achieve their goals. (frustration, aggression) or as a result of excessive pressure from both the trainer and the audience and the press, he sees his opponent as a hostile, and can perform actions to injure him in one-on-one struggle. But if we look 
at the general behavior, that is, if we look at fouls committed by professional football mags, there is a big.

We see that 5 days are instrumental (tactical) fouls are used as a tool. Here is a very fine line between fouls committed with or without the injury. The interpretation of this belongs to the referees during the match, but their control depends on both the player and the coaches. Because this behavior is learned and tactical, the player can leave the team alone as a result of losing control. That often its realization will reveal a negative value in terms of the success of the teams.

\section{References}

1. Gümüşdăg H, Yıldıran İ, Yamaner F, Kartal A (2011) Aggression and fouls in professional football. Biomedical Human Kinetics 3(2011): 67-71.
2. (1999) EPAK central referee board education planning sub-commission presidency. "Cagdas Refereeing", Football Training, T.F.F. Publication, Sweden.

3. İkizler HC (1993) Psychology of success in sports. Alpha Publications, Istanbul, Turkey.

4. Luxbacher J (1986) Violence in Sport: an examination of the theories of aggression, and how the coach can influence the degree of violence displayed in sport. Coaching-review-(Ottawa) 9:14-17.

5. Koknel (1986) Personality from anxiety to happiness. (11 $\left.{ }^{\text {th }} e d n\right)$, Golden Books Publishing House, Istanbul, Turkey.

6. Coulomb G, Pfister R (1988) Aggressive behaviors in soccer as a function of competetion level and time. Journal of Sport Behavior 21(2): 222-231.

7. Ongel HB, Günay M (1998) Psycho-social approaches to violence and aggression tendencies in sports. Turkish Journal of Social Research 2(2): 89- 17. 